\title{
As práticas do "Serviço Social activo" no âmbito das novas tendências da política social: uma perspectiva portuguesa
}

\author{
Active Social Work practices within the new \\ social policy trends: a Portuguese perspective
}

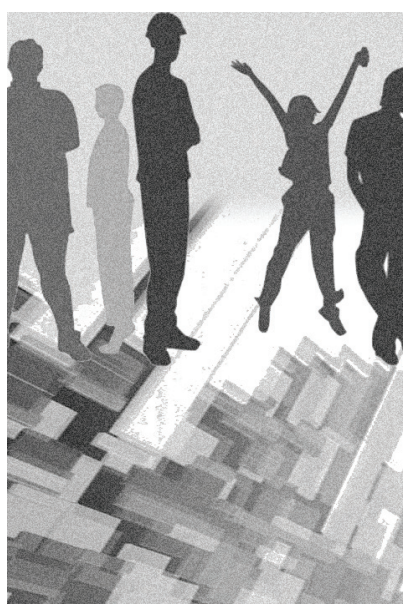

Francisco Branco*
Inês Amaro**

Resumo: Este artigo pretende discutir como a política social activa deu origem a um "serviço social activo" e que tipo de questões se levantam à profissão, tendo em conta a orientação subjacente à definição de Serviço Social da Fias. Uma das mais relevantes discussões neste domínio prende-se com a noção de empowerment segundo uma concepção que não se confina ao nível individual, mas se alarga ao nível comunitário e colectivo. A análise ensaiada baseia-se em dados recolhidos em estudos empíricos realizados em Portugal no âmbito do serviço social e da política social.

Palavras-chave: Política social activa. "Serviço social activo." Empowerment.

\begin{abstract}
This article will discuss how active social policy gave birth to an "active social work" and what kind of issues it raises to the profession, taking into account the acknowledged IFSW definition of social work. One of the most relevant discussions in this realm concerns the notion of empowerment and its extent from individual to community level. The analysis will rely on data collected from empirical studies on social work and social policy in Portugal.
\end{abstract}

Keywords: Active Social Policy. “Active Social Work.” Empowerment.

* Professor da Universidade Católica Portuguesa — Lisboa, Portugal. E-mail: fnbranco@fch.lisboa. ucp.pt.

** Doutora em Serviço Social. Faculdade de Ciências Humanas, Universidade Católica Portuguesa — Lisboa, Portugal. E-mail: ines.amaro@fch.lisboa.ucp.pt. 


\section{Introdução}

presente artigo pretende discutir a forma como as políticas sociais ac-
tivas deram lugar a um "serviço social activo" e que tipo de implicações
advém dessa mudança.
A análise desenvolve-se em três capítulos fundamentais: em primeiro lugar, enfatiza-se a relação intricada entre a instituição do Estado de Bem-Estar ${ }^{1} \mathrm{e}$ a profissionalização do Serviço Social; num segundo momento, são apontados os principais traços das mutações contemporâneas dos sistemas de bem-estar; e, finalmente, discute-se como essas mudanças afectam o serviço social, dando origem a um "Serviço Social activo".

Por fim, apontam-se as questões levantadas por essa mudança e as consequências e desafios problemáticos que coloca ao Serviço Social contemporâneo, dando especial relevo ao que vem ocorrendo ao nível das práticas profissionais.

O artigo conclui com uma reflexão sobre o lugar e o âmbito das práticas orientadas para o empowerment no contexto deste recém-surgido "Serviço Social activo".

Os dados empíricos utilizados pertencem a três pesquisas diferentes desenvolvidas pelos autores. Duas dessas pesquisas referem-se a estudos que tiveram por contexto a principal instituição de assistência social em Lisboa: uma analisou os profissionais, as suas práticas e as suas perspectivas sobre a intervenção de primeira linha (front-desk) (CET e Cesss, 2008), e uma outra empreendeu uma abordagem em profundidade junto dos utentes dos serviços de assistência social (Castro et al., 2010). A terceira fonte de dados derivou de uma investigação de doutoramento sobre as tendências e mudanças contemporâneas no Serviço Social (Amaro, 2009).

Todos os extractos foram retirados de entrevistas, maioritariamente com assistentes sociais, mas também com utentes, e de relatórios de atendimento realizados por "clientes mistério", utilizados como metodologia de recolha de dados no primeiro estudo mencionado. ${ }^{2}$

1. Utilizamos neste artigo, com idêntica significação, ainda que não conceptualmente coincidentes, as designações "Estado de Bem-Estar" (numa tradução literal insatisfatória de Welfare State), "Estado-providência", consagrado pela literatura francófono, e "Estado Social".

2. O "cliente mistério" consistiu numa metodologia de recolha de dados baseada em falsos utentes que se dirigem aos serviços de assistência social, com histórias previamente preparadas e com grelhas de observação e guião de questões a colocar ao assistente social. No final de cada entrevista o "cliente" revela a encenação ao profissional envolvido e redige um relatório. Neste caso, todos os profissionais potencialmente envolvidos nesta forma de recolha estavam conscientes de que num determinado período de tempo um 


\section{Estado de Bem-Estar e a emergência do Serviço Social como profissão}

Tal como argumenta Robert Castel (2005), o desenvolvimento do Estado de Bem-Estar e do Serviço Social estiveram intimamente ligados durante o período que se seguiu à Segunda Guerra Mundial. Desse ponto de vista, o desenvolvimento do Serviço Social e do Estado de Bem-Estar partilham de uma mesma dinâmica: o reforço do sistema de bem-estar é concomitante com a profissionalização do Serviço Social e do trabalho social em geral. ${ }^{3}$

A instituição de esquemas de política pública e a burocratização dos sistemas de política social constituíram o contexto histórico estrutural de consolidação do Serviço Social como profissão. Rapidamente a profissão tornou-se maioritariamente pública, e a sua esfera de administração da política cresceu de forma significativa. Muitos autores sustentam que nesse processo o Serviço Social foi sendo gradualmente drenado dos seus fundamentos matriciais e tornou-se numa prática administrativa e managerialista.

Historicamente, a consolidação do Serviço Social tentou combinar a responsabilidade social, o comprometimento moral e a base científica, constituindo-se "numa espécie de contrato que liga a humanidade na responsabilidade: cada um recebe o que os outros dão e cada um dá o que os outros recebem. Os seres humanos têm entre si a obrigação da solidariedade. No plano político, o solidarismo demarca-se quer do socialismo, quer do liberalismo e, no plano ético, procura reencontrar a ciência e a moral" (Martins, 1999, p. 23). Neste sentido, o propósito do Serviço Social quando da sua institucionalização era de "sustentação utópica de conciliação da concepção de vida humanisto-cristã com a dimensão capitalista das relações de trabalho" (Mouro, 2001, p. 57).

Tal como Soydan argumenta, o Serviço Social surge da associação entre os ideais de progresso humano, com uma análise científica das sociedades, e a ideia de que essa análise pode conduzir à intervenção:

[...] a prática do Serviço Social para ajudar as pessoas que necessitam de ajuda e para transformar as condições de vida das populações e melhorá-las está relacionada com

\footnotetext{
conjunto de "clientes mistério" iria aparecer no serviço, mas apenas foram informados das situações simuladas depois da primeira entrevista e antes de o profissional começar a realizar qualquer diligência.

3. O nascimento do Serviço Social como profissão é anterior à Segunda Guerra Mundial, mais precisamente, ocorreu com as origens da criação dos Estados de Bem-Estar, mas a sua expansão e consolidação teve lugar no contexto do desenvolvimento do Estado-Providência e das políticas sociais públicas a partir de meados da década de 1940.
} 
a análise científica de um determinado contexto histórico. Do ponto de vista da história das ideias, isto depende de dois factos: a origem da análise científica da sociedade durante o século XVIII e a aplicação da análise social científica e do prognóstico como instrumento para o trabalho de mudança social. (Soydan, 2003, p. 32)

A aspiração do Serviço Social como uma actividade profissional nas sociedades modernas está, neste sentido, associada com o próprio surgimento da ciência social, ou seja, com a emergência do pensamento científico como forma de analisar as sociedades e com a ideia de que as condições sociais podem e devem ser alteradas de acordo com modelos e teorias científicas. Desta forma, o espaço profissional da prática do Serviço Social é o do pacto social com vista a um ideal de progresso humano, justiça social, democracia, equidade e autodeterminação. Foi assim que o Serviço Social se consolidou como uma actividade prática, com uma base científica e uma abordagem humanista.

O modelo social europeu, com o sistema de bem-estar e políticas sociais, tornou-se no enquadramento hegemónico do Serviço Social com as necessárias implicações na estruturação da prática profissional. Argumenta-se, nesta linha, que não é possível analisar as mudanças no Serviço Social sem uma referência directa às actuais tendências da política social e pensar sobre as transformações nos sistemas de bem-estar sem tomar em consideração as suas implicações para o Serviço Social.

Com efeito, o Serviço Social pode ser considerado uma profissão da modernidade, uma vez que está fundado sobre alguns dos princípios básicos da modernidade, tais como direitos humanos, justiça social e equidade. É, desta forma, imperativo para o Serviço Social compreender que tipo de problemas advém da reconfiguração desse referencial axiológico.

Castel sustenta que o Serviço Social “clássico” (desde o fim da Segunda Guerra Mundial até meados dos anos 1970) funcionou como a parte do modelo de integração e de progresso social representada pelo Estado Social, tendo sido profundamente afectado pela própria crise do Estado Social e do progresso social (cf. Castel, 2005, p. 29).

\section{A reorientação nas políticas sociais e os seus impactes no Serviço Social}

Desde os "trinta gloriosos anos", os sistemas de bem-estar na Europa têm sido confrontados com múltiplas ameaças e desafios à sua sustentabilidade. Sendo uma marca distintiva do pacto social europeu, os fundamentos do sistema de bem-estar têm sido sempre apoiados pelos decisores políticos, embora a sua bondade venha cada vez a ser mais questionada por todos os quadrantes da sociedade. 
A partir de 1974, um conjunto de circunstâncias e factores vieram demonstrar as fragilidades do modelo social europeu. Pierre Rosanvallon foi um dos primeiros analistas a apontar a tripla natureza crítica dessa crise: financeira, ideológica e filosófica. A primeira consiste no desequilíbrio entre receitas e despesas e na primeira crise petrolífera. A crise ideológica refere-se à perda de legitimidade e à ideia crescentemente difundida do Estado como gestor incompetente (Rosanvallon, 1984). A crise filosófica surge associada ao questionamento do princípio da solidariedade perante o princípio da responsabilidade, à incapacidade do Estado de reduzir a incerteza e à tendência de redução da cobertura de riscos (Rosanvallon, 1995).

Hoje, a crescente complexidade das sociedades (pós-)modernas, a fragmentação das realidades sociais, o desaparecimento do pleno emprego, o aumento da precariedade no mercado de trabalho, em conjunto com o aprofundamento dos "factores de crise" que assinalaram o início da primeira crise do Estado-Providência, formam o pano de fundo a partir do qual toda a política social enfrenta desafios e mudanças. Essas tendências de mudança sofreram uma significativa aceleração com a atmosfera generalizada de crise, incerteza e vulnerabilidade que se instalou em diferentes domínios da realidade (financeira, económica, social, cultural, entre outras).

Com efeito, as mudanças fundamentais que se têm vindo a operar, desde os finais dos anos 1990, nos sistemas de bem-estar europeus apontam para a activação, a territorialização e a individualização da política social. Essas mudanças são parte integrante de uma mutação e reconfiguração societal mais alargada que o próprio Estado-Providência, que tem conduzido a mudanças nucleares nas concepções de solidariedade, cidadania e direitos sociais (cf. designadamente Soulet, 1998; Ion, 2005).

A figura que se segue ilustra e sumariza as principais mudanças a que se fez referência, quer na esfera societal quer na esfera do Estado de Bem-Estar.

A activação é uma das mais paradigmáticas características do novo quadro político. Em contraste com o que tem vindo a ser considerado como dispositivos de política social passivos do passado, a activação aparece como uma nova forma de entender a solidariedade, o compromisso, os direitos e deveres e o pacto social. Tem ganhado relevo um criticismo aos sistemas de bem-estar do pós-guerra fundamentado na ideia de que a universalidade e a garantia dos direitos e benefícios estimula a inactividade e a passividade dos seus beneficiários, que acabam por tendencialmente se acomodar a uma condição de dependentes das políticas sociais. A esse propósito, a nova geração de políticas sociais deve dar ênfase à questão da contrapartida, isto é: ninguém deve se beneficiar de uma medida de política social sem que activamente realize alguma acção no sentido de alterar as circunstâncias que o levaram a necessitar de recorrer ao sistema de bem-estar. 


\section{Figura 1}

Mutações societais e reconfigurações do Estado de Bem-Estar

\section{Mudanças Societárias}

- Mudança da concepção de RISCO de um modelo de risco baseado na solidariedade para um modelo de risco baseado na responsabilidade.

- Mudança da concepção de POLÍTICA da política como moral à política como regulação.

- Mudança da concepção de CIDADANIA dos direitos civis e sociais para o(s) direito(s) de autonomia (cidadania subjectiva).

\section{Reconfiguração Welfare State}

- Mudança de Modelo de Regulação do modelo keynesiano ao modelo do Estado Social Activo.

- Mudança das políticas sociais

- das políticas de integração para as políticas de inserção.

- das medidas passivas para a activação.

- da centralização à territorialização das políticas sociais.

Fonte: Branco (2009) com base em CET e CESSS (2008).

A lógica da activação entrecruza-se com a lógica da inserção. Dito de outra forma, há uma focalização no mercado de trabalho como o principal locus da integração social e uma parte significativa da intervenção social está direccionada para este fim. Neste sentido, pode dizer-se que se opera uma mudança na política social dos propósitos orientados para a integração para os da inserção. Num sentido aproximado, alguns autores defendem que no modelo social europeu se assiste a um movimento do welfare para o workfare (Alonso e Ortiz, 1996; Boyer, 2007; Paugam, 2007, entre outros).

Assim, esta ideologia contém uma concepção de cidadania activa que é entendida e avaliada em termos da participação (ou apetência para a participação) no mercado de trabalho. Tal quadro de referência aponta para uma abordagem individualista dos problemas sociais, que coloca a ênfase na apetência, desejo, disposição manifesta dos indivíduos para se comprometerem com a sociedade através do trabalho.

Mesmo reconhecendo que o modelo anglo-saxónico é muito mais orientado para o trabalho do que o modelo continental, ambos são atravessados por esta focalização na eficácia das políticas que desloca o centro do processo de intervenção para o que pode ser definido como a contrapartida, a sua contratualização com o beneficiário e a sua mensuração para posterior avaliação. 
As consequências dessa tendência de fundo para o Serviço Social são claras: a questão do estabelecimento do contrato e da negociação torna-se crítica para os assistentes sociais. Identificam-se dois aspectos implícitos e paradoxais subjacentes à ideia de contrato (de inserção social): por um lado, pressupõe-se a existência de uma relação simétrica entre as partes e a existência de efectivas oportunidades; por outro, salienta-se a fragilidade moral e a incapacidade do outro, que não é capaz de gerir a sua própria vida sem recorrer a um contrato que define os aspectos mais básicos e nucleares da vida cuja gestão está ao alcance de todos os outros.

Acresce que a intervenção social está cada vez mais confinada à instrução e ao desenvolvimento de processos administrativos, maioritariamente associados à questão do controlo. Em larga medida, a prática está a tornar-se mais instrumental que substantiva, mais preocupada com os resultados do que com os processos. Os assistentes sociais hoje dirigem a sua atenção para a apreciação do posicionamento dos indivíduos perante a adesão ao contrato e a apresentação dos resultados.

Com muita frequência os profissionais dão mostras de desconforto quanto às implicações dessa ideologia emergente para os processos de intervenção. Assim se ilustra nos seguintes exemplos:

é um poder [que os assistentes sociais têm] que humilha, submete, subalterniza o cidadão [...]. (Assistente social, docente, 2008)

[existe] uma tendência para colocar nos clientes problemas que não são de facto dos clientes, os clientes têm muitos problemas, mas são problemas que têm que ver com o sistema institucional, têm que ver com a organização institucional, têm que ver com as políticas sociais, têm que ver com transformações societárias [...], isso acontece com demasiada frequência [...]. (Assistente social, docente, 2008)

[...] muitas vezes o que é valorizado é a componente da sua [do indivíduo] responsabilidade individual e, portanto, a intervenção é feita de acordo com isso, portanto, ele é que tem de mudar, ele é que se tem de adaptar, ele é que é disfuncional [...]. (Assistente social, 2008)

Na perspectiva dos utentes, fica a ideia de que muitos dos procedimentos das "práticas activas de intervenção" estão para além da sua compreensão e da sua capacidade de lidar com um processo de intervenção no qual deveriam ter o papel principal.

Fui apanhada de surpresa; fui a um atendimento para assinar o acordo e estavam uma série de técnicos na sala e fizeram-me assinar o acordo [...] eu não sabia o que estava a assinar porque eles eram muitos, da saúde, senti-me sob pressão, eu confiei nela 
porque ela é a minha assistente social, não é? “Olhe, tem aqui os papéis, é só assinar!” E eu assinei, foi assinar e sair, está a compreender? (Utente, 2009)

O processo de territorialização e descentralização refere-se à crescente tendência de desenhar programas e medidas de política social baseadas na flexibilidade institucional e numa delimitação e administração orientadas territorialmente. Por oposição aos esquemas centralizados, generalistas e universais, nesta orientação é privilegiada uma lógica de discriminação positiva das populações e territórios (cf. Castel, 1995; Whull, 1996). Uma dimensão positiva desta tendência na política social contemporânea é a capacidade de promover medidas mais específicas e contextualizadas. Porém, essa tendência também pode ser considerada uma inclinação para a "foco-política" (Faleiros, 2001) com um impacto limitado na desigualdade e desvantagem social e/ou analisada do ponto de vista conceptual dos "regimes locais de inserção" (Bouchoux et al., 2004). Nesta perspectiva, as interacções entre os contextos socioeconómicos, os mercados de trabalho locais, os actores institucionais locais e o perfil dos utentes das políticas sociais produzem diferentes impactos na pobreza, na exclusão social e noutros problemas e necessidades sociais.

Outra dimensão convergente desse processo é, também, a cada vez mais saliente passagem de responsabilidades do Estado para o sector do voluntariado/não governamental.

Hoje, a individuação é talvez a dimensão mais reforçada nas políticas sociais em geral, e nos dispositivos de assistência social/acção social em particular (Franssen, 2003). Numa tendência que pode ser observada desde os anos 1970, a autonomia e a responsabilização assumem-se cada vez mais como um requisito normativo em todas as esferas da vida social e também no campo da política social (Breviglieri, 2008). É nesse sentido que as novas regras da política de assistência social, e a política social em geral, são orientadas por uma exigência de demonstração activa de capacidades e responsabilidades, como condição essencial para o desenvolvimento das políticas públicas de reconhecimento (Patrick, 2000, cit. in Canteli, 2006, p. 5).

Tem sido amplamente reconhecido que, sob as mutações societais contemporâneas mais vastas, o individualismo aparece como um dos processos mais marcantes. Actualmente, ser indivíduo significa ser actor, com capacidade de acção, ser sujeito de direitos e deveres, ter capacidade contratual e ser capaz de ser autónomo e autodeterminado. Robert Castel, na sua análise crítica das sociedades actuais $(1995,2009)$, sustenta que os processos de individualização são bastante problemáticos, uma vez que há um conjunto de condições que são necessárias para a realização plena da individualidade. Aqueles que estão em melhores condições tendem a aderir à racionalidade do individualismo e a desvincular-se da sociedade, 
ao passo que os que estão em maior desvantagem acabam por ser deixados sozinhos na sua incapacidade de se tornar indivíduos, nessa acepção.

Castel (1995) conceptualizou estes dois tipos de individualismo: o individualismo positivo e o negativo. Na sua perspectiva, ambos são igualmente problemáticos na sua relação com a sociedade como um todo. Mais recentemente, Castel (2009) reconceptualizou esse processo designando dois tipos de indivíduos: o indivíduo hipermoderno por excesso e o hipermoderno por defeito.

O primeiro caracteriza-se pela perda de uma noção clara de vida em sociedade e, consequentemente, de bem comum; há uma total imersão na subjectividade, com o desenvolvimento de uma cultura hedonista e psicológica; o indivíduo é visto como um fim em si mesmo e como a medida de todas as coisas; em suma, considera-se a existência de uma lei geral de autossuficiência. Por outro lado, o indivíduo hipermoderno por defeito é alguém que não é capaz de se tornar num indivíduo, com uma profunda falta de capitais sociais de suporte e sem capacidade de aceder ou criar recursos importantes para a construção da sua individualidade. Neste polo, a pessoa também tende a sentir-se socialmente desconectada/desligada (Castel, 2009, p. 424-449).

De acordo com essa perspectiva, mais do que se tratar de sinais de sucesso ou de falhanço social, importa reconhecer a existência de um fenómeno em crescimento de desconexão entre indivíduos e entre indivíduos e sociedade. É esse desligamento que Castel designa de desafiliação.

Isto significa que, cada vez mais no seu trabalho, os assistentes sociais se encontram perante pessoas que apresentam problemas sérios de vinculação à sociedade. Mais do que a privação, a escassez de recursos, a falta de emprego, estas pessoas apresentam sinais de anomia no sentido em que não são capazes de desenvolver relações positivas com a sociedade. Os assistentes sociais estão muito mais orientados para trabalhar com os indivíduos hipermodernos por defeito do que por excesso. Nestes, trata-se essencialmente de casos de sucessivas rupturas com as diferentes esferas sociais até a base da vida social, a que chegam na mais completa solidão. Veja-se, a este propósito, um exemplo,

[...] era empregado como qualquer pessoa. Casado. Divorciei-me. Vivia com a minha mulher, a minha filha e a minha mãe. Depois do divórcio a minha vida modificou-se [...]. Entretanto, morre a minha mãe. A minha filha com dezassete anos quis ser independente e saiu de casa [...]. E quando dei por mim, comecei a não pagar a renda da casa, água, luz. O meu cérebro parece que parou. Desinteressei-me. [...] Depois, quando dei por mim, recebi uma ordem de despejo [...]. Dei por mim, estava nos Restauradores a perguntar a um rapaz que ia a passar com um cartão, onde é que eu podia dormir. E foi a primeira noite que dormi na rua, nunca tinha dormido. [...] Estou 
sempre a pensar no suicídio [...]. O problema começou foi quando fiquei sem a casa, a separação, a morte da minha mãe. Eu fiquei absolutamente descontrolado e nunca mais me senti uma pessoa controlada desde essa altura. (Utente, 2009)

A respeito desses processos de desafiliação, autores como Marc-Henry Soulet (2007) referem a recente necessidade de que os assistentes sociais prestem atenção aos processos identitários dos seus utentes, com vista a reconstruir identidades, dar sentido e perspectivar trajectórias alternativas.

Todas as mudanças na política social assinaladas apresentam, de forma latente, questões problemáticas para a intervenção em Serviço Social. Nesta base questiona-se até que ponto o Serviço Social contemporâneo está a contribuir para a mudança social e individual ou está estabelecido como um campo especialista na gestão da pobreza. Neste sentido, a nossa hipótese de trabalho é a de que perante um estado social activo emerge um "serviço social activo" com novos desafios e questões.

\section{Rumo a um "Serviço Social activo"?}

Como já foi anteriormente referido, considera-se que os propósitos, procedimentos e objectivos do Serviço Social não são imunes aos ventos de mudança da política social contemporânea. Com efeito, sustenta-se a tese de que as linhas de mudança apresentadas na política social aprofundaram o carácter instrumental da profissão.

Por carácter instrumental da profissão entende-se o acentuado fenómeno, ainda mais evidente no sector público, ${ }^{4}$ de focalização do assistente social nos procedimentos e na importância de seguir todos os passos previstos, em detrimento da avaliação diagnóstica e global da real situação dos utentes; de preocupação com os resultados, mais do que com o processo; de profunda confusão entre eficácia da intervenção e uma quantificação cega das práticas, e de sobrevalorização da importância dos assim designados procedimentos técnicos contra uma subvalorização dos impactos reais dos processos de intervenção na transformação individual e social.

E acho que era necessário que se reorganizasse o trabalho numa perspectiva mais de mudança do indivíduo. Esta questão do número médio de atendimentos por técnico semanal é uma coisa muitíssimo exagerada quanto a nós classe profissional, quanto a

4. Apesar de o processo de transferência de competências do Estado para o terceiro sector, ao abrigo dos protocolos, estar a apresentar um "efeito de contaminação" deste sector com as tendências observadas no sector público. 
mim, mas de facto são regras [...] Em média, em dois meios tempos, neste momento a orientação são 16 atendimentos. $\mathrm{O}$ que é muitíssimo, porque nesta perspectiva do acolhimento tenho que perceber quem é aquela pessoa que vem aos serviços [...]. (Assistente social, Serviço de Assistência Social, Atendimento Social, 2007)

Assim, pode argumentar-se que com o desenvolvimento dos sistemas de bem-estar, o Serviço Social tem-se transformado gradualmente em apenas uma "peça da engrenagem" dos sistemas administrativos e burocráticos de aplicação e execução das medidas de política pública. Esta tendência quase irresistível tem, em muitos casos, conduzido a uma confusão entre Serviço Social e actividades de gestão tecnocrática e administrativa da esfera social, que encontra nos enquadramentos legais, mais do que nos princípios teóricos e axiológicos, um fundamento para a prática. Este excesso de burocratização, aliado à racionalidade ultrainstrumental do mundo contemporâneo, drena a profissão dos seus conteúdos mais substantivos, designadamente do papel crítico desempenhado pelas diferentes agendas política, ética e teórica do Serviço Social, e submerge a prática profissional em preocupações procedimentais, instrumentais e managerialistas.

A esse processo de "finalismo metodológico" (Amaro, 2009), querendo significar que, mais do que a pessoa, a relação profissional, a coconstrução de narrativas e a consciência dos direitos e dos valores, assume primordial importância na prática profissional a capacidade de utilizar as técnicas de avaliação e planeamento, os níveis de eficiência e eficácia alcançados e o número de benefícios atribuídos. Neste sentido, a intervenção em Serviço Social torna-se cada vez mais burocrática e managerialista e cada vez menos relacional e política.

Só que o tempo é muito pouco, e por isso devia haver [...] a nível de burocratização devia ser menos e o trabalho administrativo não ser tanto imputável ao assistente social. Há o aspecto burocrático das situações, dos processos, do Sias, e depois também os processos do Rendimento de Inserção Social, que requer muito tempo, mesmo muito tempo, não esquecendo também a estatística mensal. (Assistente social, Serviço de Assistência Social, Atendimento Social, 2007)

Uma profissional com responsabilidades de organização de um serviço de atendimento coloca as suas reflexões sobre esse material da seguinte forma:

[...] um técnico de Serviço Social faz toda esta avaliação, faz o diagnóstico, faz um acordo seja do que for e alguém vai ter de acompanhar, pode ser o técnico de Serviço Social ou delegar noutro técnico com formação [...]; penso que o educador social desempenharia esse papel muito bem, acompanhar essas acções [...]. (Assistente social, Serviço de Assistência Social, Coordenação, 2008) 
Como se verifica nesses testemunhos, são deixadas aos assistentes sociais as tarefas mais burocráticas e administrativas, fazendo com que a esfera mais substantiva, ou se se preferir mais nobre, da intervenção - o estabelecimento de relações empáticas, a capacidade de ajudar e apoiar os outros, o desenvolvimento da confiança e da segurança - tenda a cair nas mãos de outros profissionais.

Seguindo essa linha, assiste-se ao aparecimento de abordagens profissionais à prática no sentido da análise e gestão do risco, do managerialismo, da prática baseada na competência ou baseada na evidência (evidence-based practice; competence-based practice) e da gestão do cuidado. Todas essas tendências desenvolvem uma complexa rede de procedimentos que o trabalhador no terreno deve seguir, supostamente testados e com garantias de eficiência, que atribuem aos meios o estatuto de fins e tomam como fundamento da profissão o rigor na aplicação de instrumentos. O conceito proposto de finalismo metodológico é precisamente utilizado porque se verifica que o cumprimento dos passos metodológicos previstos se torna um fim em si mesmo e contém o que de mais importante é tido em conta nas práticas profissionais.

Um "cliente mistério", metodologia utilizada para a recolha de dados sobre o atendimento, notou que durante a primeira entrevista com o assistente social, "Resta a dúvida: a técnica fez exclusivamente as perguntas que não podia deixar de fazer, por quê? Porque poupa o tempo da resposta ou porque não tenta encontrar uma solução ao caso específico do utente que tem à frente?" ("Cliente mistério", 2007).

De facto, ficou claro neste estudo que é exercida uma enorme pressão sobre os profissionais no sentido da demonstração de resultados, o que se tem traduzido numa lógica de realizar o máximo possível de atendimentos e de disponibilizar uma "resposta" no período mais curto possível. Em paralelo, é também entendido como crucial o papel de verificação da veracidade das situações expostas pelos utentes. Isto significa que, com o tempo disponível, tudo o que o assistente social pode fazer é tomar nota do pedido do utente e assegurar que o indivíduo tem direito à prestação em causa. Enquanto alguns profissionais parecem pensar que isto é o que compete a um assistente social, outros sentem-se desconfortáveis neste papel. Para estes os referenciais éticos e metodológicos apontam para a importância de constituir relações empáticas, que promovam a participação e o empowerment, com vista a atingir a autónoma do utente e a perspectivar outros níveis de intervenção.

[...] o facto de o técnico não dispor de muito tempo faz com que por vezes se esqueça de algumas dimensões que são importantes na intervenção social. E uma das dimensões é a inter-relação com os outros parceiros, e o técnico acaba por ficar tão aturdido com os atendimentos que lhes resta pouco tempo para esta dimensão que eu considero importante. Acho que devíamos ter mais algum tempo para trabalhar numa 
relação comunitária, com outros parceiros, procurar respostas mais ajustadas às necessidades da população. Eu acho que existe uma pressão sobre os técnicos que não é muito facilitadora para isso. (Assistente social, Serviço de Assistência Social, Coordenação, 2007)

Estas preocupações contrastam com uma forte instrumentalidade dos processos de intervenção. Quando se tentou desenhar uma topografia da intervenção encontrou-se uma fase de avaliação-diagnóstico centrada sobretudo numa abordagem de verificação da condição de recursos (means-test approach), uma atitude de teste perante os utentes, um escasso recurso a uma abordagem biográfica e a uma visão global/holística da situação do utente. A esse propósito, Webb argumenta que "o Serviço Social está a abandonar a abordagem holística para trabalhar com os clientes no sentido de se alinhar com a política dominante da gestão neoliberal do cuidado" (Webb, 2006, p. 7). Este fenómeno pode também ser ilustrado pelas próprias palavras dos profissionais:

Portanto há que perceber isso, para ver se a pessoa está a ser verídica ou não na informação que está a ser passada, embora eu depois posteriormente, logicamente que quando a pessoa me diz que estão a estudar, este contacto, independentemente de ser feito com os locais para se perceber [...] eu tenho que articular conforme disse há bocadinho com os vários parceiros, neste caso as escolas, para saber se efectivamente isto é real ou não e se de facto aquele menor está ou não está a estudar consoante a situação que a pessoa me referiu. Portanto há que fazer esta articulação e este cruzamento. (Assistente social, Serviço de Assistência Social, Atendimento Social, 2007)

No que respeita à fase do plano de intervenção, verificou-se que uma visão mais compreensiva do projecto de vida do utente está quase completamente ausente e que persiste uma forte tendência para a instrumentalização e estandardização das respostas às diferentes situações colocadas. Só raramente os recursos e iniciativas próprios dos utentes foram tidos em linha de conta e praticamente não se encontra um trabalho de reconstrução das narrativas e identidades do utente. Perante uma crescente dificuldade e complexidade das situações, os processos de intervenção tendem, paradoxalmente, para uma simplificação e redução aos níveis puramente instrumentais.

A técnica não soube valorizar os problemas reais do utente [...]. Aconteceu com as questões [...] da independência profissional (tendo encaminhado para o centro de emprego quando o utente explicou que o que queria era não trabalhar por conta de outrem porque já várias vezes não tinha sido pago pelo trabalho realizado), valorizou excessivamente a formação profissional apesar de o utente ter explicado que sabia trabalhar em electricidade. ("Cliente mistério", 2007) 
Noutra dimensão, encontrou-se um uso escasso da contratualização e da avaliação. O primeiro, mais do que um instrumento para estimular a cidadania, é sobretudo usado como um instrumento de introdução de uma lógica de responsabilização do utente e apenas residualmente para estabelecer as responsabilidades dos serviços e da sociedade como um todo perante os indivíduos. À segunda raramente se faz referência e, quando esta ocorre, os assistentes sociais privilegiam o seu uso como uma ferramenta de controlo do percurso do utente. Torna-se, assim, evidente que nem o contrato é utilizado como instrumento de coconstrução com o cliente, nem os procedimentos de avaliação são sistematicamente definidos.

Confrontá-lo com essa situação e tentar perceber o porquê de ele não estar a concretizar essa aç̧ão [...]. (Assistente social, Serviço de Assistência Social, Atendimento Social, 2007)

Quando há aquisições, quando há avanços da parte da pessoa, quando se consegue arranjar trabalho, mesmo que não cumpra aquele prazo que foi estipulado. Na maior parte das vezes não se estipulam prazos, aliás o prazo é o prazo do subsídio; no fundo, claro que existe o prazo que corresponde ao prazo do subsídio. Penso que existe, mas mesmo que não cumpra o tal prazo, mas se se vê que é uma pessoa empenhada... (Assistente social, Serviço de Assistência Social, Atendimento Social, 2007)

Simultaneamente, com muita frequência, os sistemas tecnológicos supostamente de apoio, que deveriam facilitar a gestão do volume das situações sociais, introduzem outros níveis de dificuldade e entropia que colocam ainda mais em questão a consistência do processo de trabalho.

[...] mas o sistema é tão lento que nós estamos um dia para fazer um plano de inserção

[...] isto também é tempo, tempo que nós perdemos em frente ao computador [...]. (Assistente social, Serviço de Assistência Social, Atendimento Social, 2007)

[...] temos um sistema, muito sobrecarregado, muito lento, que o que nós poderíamos desenvolver numa hora desenvolvemos numa tarde, portanto isso à partida é um recurso limitativo. (Assistente social, Serviço de Assistência Social, Atendimento Social, 2007)

A utilização dos sistemas exige tal dispêndio de tempo que acaba por parecer que é o tempo para realmente estar com os utentes a construir em conjunto, por exemplo, o plano de inserção que se torna numa dimensão negligenciável do trabalho de acompanhamento social.

Em suma, os processos de intervenção condensam tensões, paradoxos e contradições com os quais é muito difícil lidar na prática, em paralelo com a pressão para resolver problemas e demonstrar alguns resultados imediatos. 
Com propósitos ilustrativos, a figura que se segue revela como estas tensões se colocam no contexto da intervenção (Figura 2).

Parece que num contexto histórico em que os públicos mais vulneráveis precisam mais do que nunca de estabilidade, segurança e de processos de intervenção e acompanhamento longos e multidimensionais, há uma ideologia hegemónica que faz a apologia do imediatismo e que inibe o desenvolvimento de uma intervenção mais alargada e profunda. Persiste um paradoxo que coloca lado a lado formas de acção ultrainstrumentais e um insistente discurso da individualidade, da construção conjunta de narrativas e da importância de reconstruir e/ou reforçar o "trabalho" sobre as identidades.

\section{Figura 2}

Lógicas de ação do Serviço Social no acompanhamento social

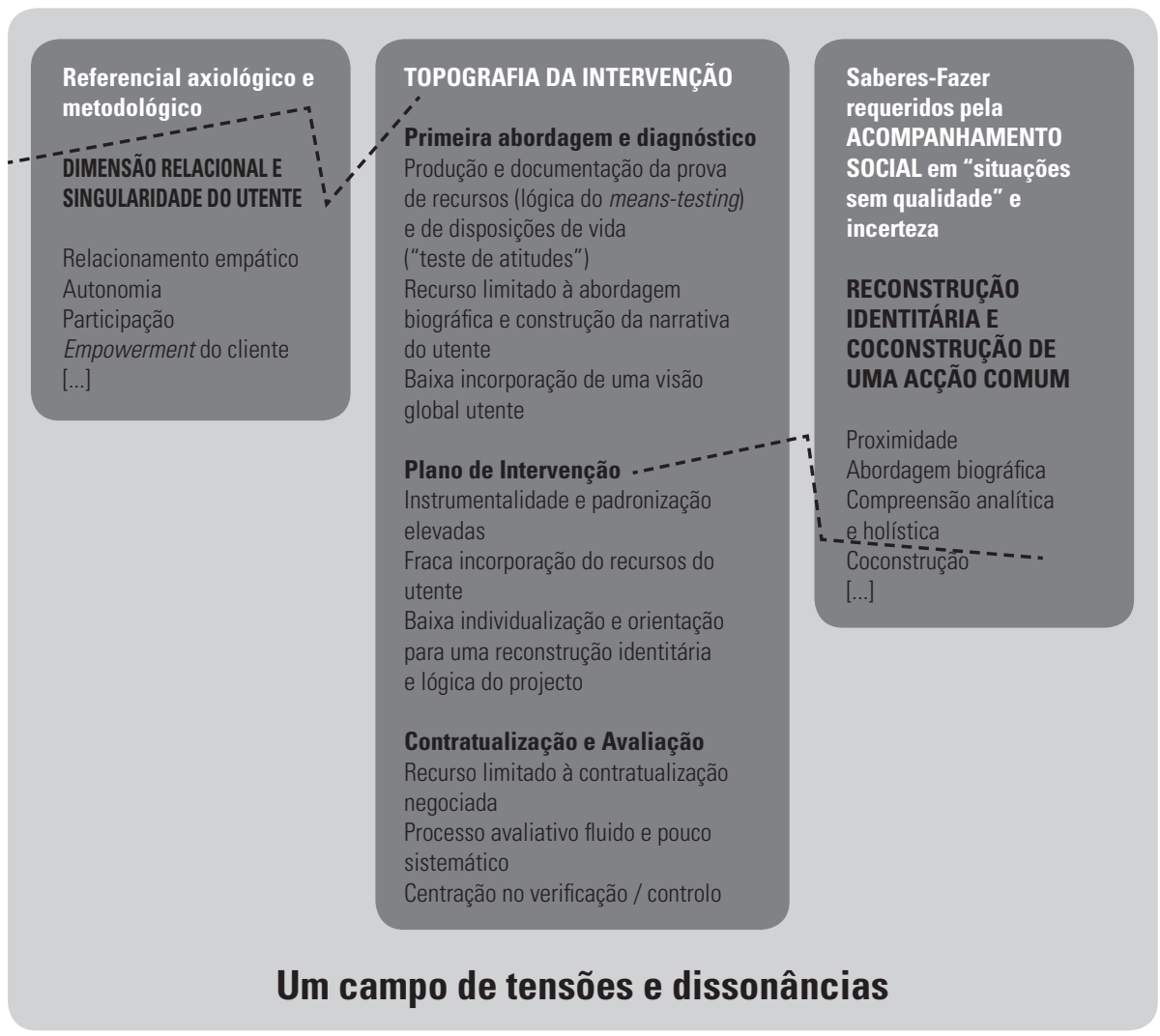

Fonte: Branco (2009) elaborado com base em CET e CESSS (2008). 
O Serviço Social no singular (Ion, 1998) implica uma relação profissional contínua e de longo prazo, de natureza interactiva, contextualizada e pouco codificada em regras institucionais. É largamente esta a proposta de autores como Ion (1998), Soulet (2005), Astier (2007), Duvoux (2008), Branco (2008), entre outros, e que só em termos retóricos está a ser seguida por um "serviço social activo", instrumental, estandardizado, acorrentado ao discurso da eficácia e da mensuração de resultados e focalizado nos resultados.

Apesar de o reconhecimento do outro na sua especificidade ser um aspecto fundamental da intervenção, o perigo deste discurso reside na sua excessiva focalização no que Soulet (2007) designa de "estereotipo de perfectibilidade", que põe como subjacente ao quadro de referência de análise a ideia de que os indivíduos são a fonte dos seus próprios problemas e simultaneamente o recurso para a sua solução tendo, como corolário, a responsabilidade por conduzir a sua própria vida. Não obstante a inegável força da vontade individual, este racional da subjectividade esbarra com fenómenos objectivos como o desemprego massivo, a precariedade das relações laborais, a fragilidade das redes sociais, o esbatimento das estruturas tradicionais de socialização e de solidariedade, entre outros. Estes compõem as condições externas de vulnerabilidade a que os indivíduos estão expostos nas sociedades contemporâneas.

É neste sentido que vários autores assinalam o paradoxo de converter défices de integração em questões individuais. As intervenções sociais ficam, desta forma, ameaçadas pela preponderância do que Dubet (2004) designa de "regra da interioridade", isto é, pela propensão para olhar apenas para as razões individuais explicativas de uma situação e para mobilizar unicamente os recursos pessoais para a sua superação. Tal como apontam Astier e Duvoux (2006), o principal desafio é o de compatibilizar a promoção da individuação moderna sem reduzir o "direito à cidade".

Esta problemática coloca os pontos de questionamento da contribuição do Serviço Social contemporâneo para o reequacionar da questão social e o refundar de um novo pacto social.

Este compromisso requer um pensamento crítico sobre as influências da lógica da activação na intervenção, sendo crucial que o assistente social seja capaz de se libertar da jaula de ferro da tecnocracia e não desista do conteúdo mais substantivo da profissão. Defende-se, em consonância com Dominelli, que

o Serviço Social atravessa um tempo de turbulência. Necessita de uma nova visão que avance com uma cidadania activa para os pobres - uma cidadania de iguais, que requer uma mudança pessoal e estrutural da ordem social existente. As actuais tecnologias de governação produziram um enorme desperdício de talento humano e causa- 
ram um sofrimento inaudito. Estes procedimentos têm que ser substituídos por outros enraizados na equidade entre pessoas que partilham recursos, se tratam mutuamente com dignidade e respeitam os recursos físicos e sociais do planeta como uma herança de todos e de cada um e da comunidade. Esta é a base de uma nova visão capacitadora do Serviço Social. (Dominelli, 2004, p. 253)

Nesta perspectiva, faz sentido estabelecer um nexo claro entre as noções e perspectivas de empowerment, as tendências de individualização e as lógicas de acção dos dispositivos de política social no contexto do Estado Social activo. É esta análise que em seguida se ensaia.

\section{Estado social activo, Serviço Social e empowerment}

O universo conceptual da noção de empowerment cobre um alargado conjunto de aspectos e de sentidos. O reconhecimento da polissemia do termo implica a existência de uma pluralidade de concepções de empowerment num eixo contínuo polarizado pelas dimensões individual e colectiva da mudança.

Adopta-se aqui a noção de empowerment proposta por Le Bossé (2003), que sustenta que o conceito tem pelo menos quatro componentes fundamentais: 1) a capacidade de influenciar a realidade de acordo com as suas aspirações; 2) a relação existente entre factores sociais, características individuais e a sua implicação na leitura, interpretação e acção sobre a realidade; 3) conhecimento do exacto contexto da prática; e 4) participação de todos os actores envolvidos e o estabelecimento de objectivos claros. Considera-se, neste sentido, toda uma dimensão de trabalho que aponta para a conscientização e que ultrapassa o mero nível individual. Adopta-se, desta forma, um entendimento de empowerment em termos de um (desenvolvimento de um) poder para agir, uma vez que, ainda secundando Le Bossé, o empowerment é precisamente caracterizado por esta conexão entre o colocar o sujeito em acção e a disponibilidade de recursos que essa acção requer.

A perspectiva do empowerment continua a ser referencial para os quadros de acção dos assistentes sociais, embora seja hoje evidente a necessidade de integrar as diferentes esferas da intervenção social e a da vida social, para além do domínio do individual. É cada vez mais reconhecido o papel estratégico crucial das dimensões comunitária e estrutural na intervenção direccionada para o empowerment.

Se se posicionar numa perspectiva exclusivamente individual, essa abordagem corre o risco de se transformar em apenas mais uma retórica que aprofunda fenómenos de isolamento social e individualismo por via de uma transferência excessiva para os ombros dos indivíduos de culpabilidade/responsabilização pelas vulnerabilidades 
sociais. Com efeito, de acordo com essa lógica, uma vez capacitados, dependerá exclusivamente da vontade individual o desenvolvimento de trajectórias de integração.

Sob esta perspectiva, o Serviço Social está longe de incorporar uma prática emancipatória e muito mais próximo dos propósitos de controlo e regulação. Na verdade, torna-se hoje importante descodificar as orientações subjacentes ao discurso do empowerment, se se pretende compreender a real natureza das práticas existentes.

Tomando o contrato como exemplo, verifica-se que se for entendido como um pacto entre o assistente social e as instituições sociais, em representação da sociedade, e o utente, pode e provavelmente deve ser uma estratégia importante para desenvolver um entendimento comum do mundo e das situações expostas entre os actores envolvidos. Pode constituir-se como uma ferramenta de suporte ao empowerment, à reconstrução de identidades e à discussão sobre o significado e o papel da contrapartida. Pelo contrário, tem vindo a ser fundamentalmente utilizado como um dispositivo de controlo e um meio para "objectivar" a intervenção, reduzindo-a a um conjunto de acções a realizar. Paradoxalmente, mesmo quando é usado como uma forma de responsabilização, essa preocupação nunca incorpora a responsabilidade própria dos serviços, dos profissionais e da sociedade como um todo no sentido de criarem as oportunidades necessárias a uma integração social plena.

[...] chegamos ao ponto em que aquela acção tanto para nós como para o utente é considerada necessária, a pessoa compromete-se a ir a determinado sítio e nós depois confrontamos, entramos em contacto com essa instituição para saber efectivamente se a pessoa foi, se está a cumprir, se não está a cumprir, e depois se for necessário vamos confrontando a pessoa com esses factos [...] (Assistente social, Serviço de Assistência Social, Atendimento Social, 2007)

Mas mesmo quando nos colocamos num nível meramente individual, a perspectiva do empowerment não pode ser utilizada apenas como forma de transferir a responsabilidade para os indivíduos. De acordo com Ninacs, o empowerment individual é sustentado por quarto esferas: participação, competências, autoestima e consciência crítica. Trata-se de um encadeamento simultâneo de etapas das diferentes esferas, que em conjunto e em interacção proporcionam a passagem de um estádio sem poder a um estádio no qual o indivíduo se torna capaz de agir de acordo com as suas próprias escolhas (Ninacs, 2003, p. 23).

Considera-se que essa nova geração de políticas sociais encerra dois movimentos associados: um dirigido à construção do indivíduo como pessoa, com uma identidade específica; e outro que aponta para o indivíduo como pessoa contratual e imputável. Primeiro, assume-se uma existência social, depois reconhece-se poder para agir; esta questão deve entroncar com a ligação entre os níveis individual e colectivo (Le Bossé, 2003). 
É interessante verificar nos discursos dos profissionais diferentes concepções de empowerment, sendo que todas tendem a assentar na esfera individual. Para uns, trabalhar o empowerment consiste em informar; para outros, trata-se sobretudo de disponibilizar formação e educação às pessoas; para outros ainda refere-se a uma dimensão de promoção da cidadania e de dar poder às pessoas no sentido de essas se tornarem capazes de reivindicar os seus direitos, como se pode ilustrar com recurso aos discursos dos profissionais.

Por exemplo, há pessoas que têm enormes insuficiências e nem sequer sabem que determinado serviço existe ou como recorrer a esse serviço. Nós depois vamos conseguindo trabalhar essas questões com essas pessoas e ao fim de algum tempo já vemos que essas pessoas já conseguem ir sozinhas e depois já conseguem identificar outros serviços que também as podem apoiar ou orientar noutras questões. É um exemplo. (Assistente social, Serviço de Assistência Social, Atendimento Social, 2007)

Mas claro que o empowerment é importante, isso significa dar-lhes instrumentos, significa estar com eles de uma forma mais afincada, se calhar de uma forma mais sequencial, de uma forma mais passo a passo, de modo a que por si próprios consigam efectivamente caminhar sem qualquer tipo de ajuda. Se calhar só precisará depois numa fase intermédia de alguns aconselhamentos ou algumas sugestões, se calhar numa fase terceira ou numa fase última já nem precisará nada de nós e será totalmente autónoma [...] mas há muitas situações em que não se chega a esse nível. Muitas mesmo! (Assistente social, Serviço de Assistência Social, Atendimento Social, 2007)

Ainda que grande parte dos assistentes sociais do atendimento considere que não pode ultrapassar o nível de intervenção individual, reconhece que o Serviço Social comunitário se apresenta como uma esfera crucial para a promoção de mudanças relevantes. Isto significa que na era da individualização, em que é colocada uma grande ênfase na subjectivação e individuação de políticas e da intervenção, o trabalho grupal e comunitário continua a ter um papel-chave no perspectivar de formas alternativas de responder aos problemas sociais. Os profissionais, tendo consciência desse papel, sentem-se de alguma forma impotentes para o desempenhar ou cépticos em relação às suas efectivas possibilidades.

Cada vez mais temos que trabalhar com a comunidade e com os parceiros da comunidade. Continuarmos a trabalhar sozinhos não se vai para lado nenhum! A culpa se calhar é um bocadinho nossa, porque a [...] sempre viveu um bocado centrada em si e procura em si as respostas (Assistente social do atendimento, coordenador, 2007)

Na concepção adoptada, a intervenção em Serviço Social deve ter uma intencionalidade para o empowerment individual, que forneça aos indivíduos ferramen- 
tas, capacidades e autonomia para interpretrar e mudar a sua própria condição, que remeta para uma dimensão mais colectiva. Refere Faleiros (1996, p. 12)

não se trata apenas de desenvolver a advocacia ou de encorajar e implementar uma maior capacidade de resolver problemas nos utentes, mas acima de tudo de entender e intervir no próprio processo de opressão e fragilização a diferentes níveis, de forma que um processo de mudança de trajectória e de fortalecimento do utente sejam combinados.

De facto, a perspectiva do empowerment deve estar atenta ao jogo entre as capacidades individuais e as oportunidades estruturais, uma vez que umas perdem sentido sem as outras.

Em suma, a perspectiva adoptada segue a proposta de Le Bossé de entendimento do empowerment como o (desenvolvimento do) poder de agir, uma vez que o empowerment é precisamente caracterizado pela combinação da mobilização para agir com a disponibilidade de recursos requeridos para essa acção. Os processos de empowerment pressupõem a existência de recursos individuais (competências, eficácia pessoal, capacidade de conceber e realizar um projecto, entre outras) e de recursos colectivos (as existência de possibilidades individuais e colectivas de acção, disponibilidade de recursos financeiros, de informações, as condições de acesso e utilização de serviços, entre outras) (Le Bossé, 2003).

Com a crescente complexidade do mundo actual, muitos profissionais revelaram o sentimento de que apenas conseguem tocar a superfície da realidade social, pois não têm tempo suficiente para ir mais longe. Acresce a tendência que têm para pensar que é muito difícil, se não impossível, trabalhar o empowerment com o tipo de pessoas que se dirigem aos serviços de assistência social. Neste sentido, está claro entre os profissionais que há, pelo menos, dois níveis de intervenção: a individual e a colectiva.

O investimento comunitário implica que as coisas sejam perspectivadas a médio e a longo prazo, mas se calhar os resultados inerentes a essa mesma intervenção provavelmente irão ter outra [...] poderão ser uma mais-valia e poderão ser elementos detentores de algumas situações. Se calhar o atendimento [...] sinto que talvez as coisas sejam muito vistas à flor da pele, não conseguimos se calhar trabalhar tanto, ir às causas. Provavelmente se a dimensão da intervenção fosse outra talvez conseguíssemos chegar lá. (Assistente social, Serviço de Assistência Social, Atendimento Social, 2007)

Seja como for, parece que há qualquer coisa invertida quando os assistentes sociais do atendimento, que é o locus por excelência de construção de um espaço de aproximação e compreensão do utente, assinalam a falta de tempo e de condições para explorar as situações individuais, para identificar as causas dos seus problemas e para relacionar as situações umas com as outras de forma a equacionar respostas colectivas para os problemas. 
Ressaltou que os assistentes sociais não estão a fazer este trabalho porque o seu tempo é subsumido na linha de montagem dos atendimentos e da atribuição de subsídios. Nessa "luta" não chegam sequer a ter uma percepção sobre quais são os resultados do seu trabalho. Parece que o Estado Social activo produz as condições sociais e institucionais para um "Serviço Social activo", e, simultaneamente, para um "Serviço Social fordista".

Posto isto, as questões que se colocam são as seguintes: Que interesses serve esse tipo de prática profissional do Serviço Social? Quem é empoderado com esta abordagem?

\section{Considerações conclusivas}

O Serviço Social, ao longo do seu percurso histórico, passou por inúmeros processos de transformação. Nas sociedades contemporâneas, as perspectivas e as lógicas em torno do Estado de Bem-Estar, em geral, e da política social, em particular, constituíram um ponto de viragem no sentido da política social activa. Essas mudanças deram lugar de destaque aos princípios advindos de uma racionalidade instrumental, focada na eficácia, na produção de resultados, na apertada definição de procedimentos e na contratualização.

Tal como McDonald (2006) o coloca, em Serviço Social ficar-se apenas pelos princípios da racionalidade e da eficiência da (evidence-based) prática, estreita perigosamente o escopo da profissão, em termos da sua acção e projecto. É neste sentido que se considera ser relevante questionar as consequências do estabelecimento de um "Serviço Social activo" que corresponda a uma política social activa.

De facto, verificou-se a existência de uma forte tendência para o aprofundamento das dimensões administrativas e gestionárias da profissão de uma forma que pode pôr em risco a própria integridade identitária do Serviço Social. Encontra-se no terreno uma tendência para reduzir a crescente complexidade das situações, evitando o seu conhecimento em profundidade. Webb refere-se a esse fenómeno apontando a inclinação para a redução da complexidade do real através da superficialidade dos processos de geração de dados no terreno (que não vão ao âmago das situações) e que dão lugar à emergência de um assistente social administrativo (Webb, 2006, p. 141-150).

Está-se, então, hoje em confronto com uma prática profissional mista, que combina traços das novas e velhas perspectivas da política social. Do passado, as práticas mantêm os propósitos de controlo e de estandardização; do presente, incorporam a individuação, a contratualização e a segmentação das respostas.

$\mathrm{O}$ discurso do empowerment tanto pode ser de resistência como de reforço destas disposições. Irá reforçar as práticas activas quando for entendido como uma 
abordagem exclusivamente centrada nas capacidades individuais. Será resistente quando for entendido como um equilíbrio entre capacidades e oportunidades, com uma inegável articulação entre os níveis individual e comunitário.

Esta abordagem básica à perspectiva do empowerment parece estar longe de ser plenamente entendida pelos profissionais e responsáveis políticos. Assim, e de forma paradoxal, encontram-se linhas de montagem nos serviços de atendimento, com a preocupação fundamental de fazer a correspondência entre tipos de utente e tipos de recursos, que, em simultâneo, se dirigem aos utentes como indivíduos responsáveis pelas suas próprias trajectórias.

Neste processo, o Serviço Social vê-se fortemente constrangido pelas condições socioinstitucionais presentes para realizar o que pode ser entendido como o cerne da sua profissionalidade: acompanhar utentes, coconstruir projectos de vida, reconstruir identidades e, entre outros, promover políticas de reconhecimento e de justiça social de acordo com as necessidades e aspirações das pessoas.

Em conclusão, pode afirmar-se que a intervenção no âmbito do "Serviço Social activo" estreita de tal forma o horizonte para a prática que, em última instância, esvazia o Serviço Social da sua alma, aspirações e propósitos éticos e políticos.

Recebido em 15/8/2011 - Aprovado em 5/9/2011

\section{Referências bibliográficas}

ALONSO, Luis Enrique; ORTIZ, Lourdes Pérez. Trabajo para todos? Um debate necesario. Madrid: Ediciones Encuentro, 1996.

AMARO, Maria Inês. Urgências e emergências do serviço social contemporâneo: contribuíos para a discussão dos fundamentos da profissão, 2009. Tese (Doutorado em Serviço Social) — Faculdade de Ciências Humanas da Universidade Católica Portuguesa, Lisboa. (Texto policopiado.)

ASTIER, Isabelle; DUVOUX, N. L'institutition de la dignité dans la société contemporaine: réflexions à partir du cas français. In: (Ed.). La societe biographique: une injonction à vivre dignement. Paris: L'Harmatttan, 2006. p. 15-31.

. Les nouvelles regles du social. Paris: PUF, 2007.

BOSSE, Y. De 1'"habilitation" au "pouvoir d'agir": vers une appréhension plus circonscrite de la notion d'empowerment. Nouvelle Pratique Social, n. 16, p. 30-51, 2003.

BOUCHOUX, J.; HOUZEL, Y.; OUTIN, J.-L. Revenue minimum d'insertion et transitions: une analyse des inégalités territoriales. Revue Française des Affaires Sociaux, n. 4, p. 107-132, 2004. 
BOUCHOUX, Jacques et al. Revenu Minimun d'Insertion et marché du travail: les "régimes locaux d'insertion". Paris: Commissariat Général du Plan, mars 2004.

BOYER, Robert. Comment concilier solidarité social et efficacité économique à l'ère de la globalisation: une lecture régulationniste. In: PAUGAM, Serge (Org.). Repenser la solidarite: L'apport des sciences sociales. Paris: PUF, 2007. p. 887-914.

BRANCO, Francisco. Acção social, individuação e cidadania: a construção do acompanhamento social no contexto do estado social activo. Cidades, Comunidades e Territórios, Lisboa, n. 17, p. 81-91, dez. 2008.

. Social action, individuation and citizenship: the social accompanying and activation measures under the scope of social assistance policies. Presentation 1st Ensact Join European Conference, Dubrovnick, Apr. 2009.

BREVIGLIERE, M. L'individu, le proche et l'institution: travail social et politique de l'autonomie. Informations Sociales, n. 145, p. 92-101, 2008.

CASTEL, Robert. Les metamorphoses de la question sociale: une chronique du salariat. Paris: Fayard, 1995.

. Devenir de l'État providence et travail social. In: ION, Jacques (Ed.). Le travail social en débat [s]. Paris: La Découvert, 2005. p. 27-49.

La montée des incertitudes: travail, protections, statut de l'individu. Paris: Ed. du Seuil, 2009.

CASTRO, Alexandra; GUERRA, Isabel (Org.). Os caminhos da pobreza: perfis e políticas sociais em Lisboa. Lisboa: SCML Editora, 2010.

CET; CESSS. Acolhimento e construção da autonomia dos clientes na Santa Casa da Misericórdia de Lisboa. Relatório final. Lisboa, 2008. v. 2.

DOMINELLI, Lena. Social work: theory and practice for a changing profession. Cambridge: Polity Press, 2004.

DUBET, François. Préface. In: CASTRA, Denis. L'insertion professionnelle des publics précaires. Paris: PUF, 2004.

DUVOUX, N. L'autonomie, fiction nécessaire de l'insertion? Disponível em: < http://www. cipidf.org/article.php3?id_article=4026>. Acesso em: 12 maio 2008.

FALEIROS, Vicente de Paula. O paradigma de correlação de forças e estratégias de acção em serviço social. In: IAMAMOTO, Marilda Villela et al. Metodologias e técnicas do serviço social. Brasília: Sesi-DN, 1996. p. 21-30.

. Desafios do serviço social na era da globalização. In: MOURO, Helena; SIMÕES, Dulce (Org.). 100 anos de serviço social. Coimbra: Quarteto, 2001. p. 313-349. 
FALEIROS, Vicente de Paula. O serviço social no mundo contemporáneo. In: FREIRE, Lúcia; FREIRE, Silene; CASTRO, Alba de (Org.). Serviço social, política social e trabalho: desafios e perspectivas para o século XXI. São Paulo: Cortez, 2006. p. 23-44.

FRANSSEN, A. Le sujet au coeur de la question sociale. La Revue Nouvelle, n. 12, p. 10-61, 2003.

ION, Jacques. Le travail social au singulier. Paris: Dunod, 1998. Introduction. In: (Ed.). Le travail social en débat[s]. Paris: La Découvert, 2005. p. 5-24.

MARTINS, Alcina. Génese, emergência e institucionalização do serviço social português. Lisboa: Fundação Calouste Gulbenkian, 1999.

McDONALD, Catherine. Challenging social work: the contexts of practice. Nova York: Palgrave MacMillan, 2006.

MOURO, Helena. Serviço social: um século de existência. In: ; SIMÕES, Dulce (Org.). 100 anos de serviço social. Coimbra: Quarteto, 2001. p. 23-60.

NINACS, William. L'empowerment et l'intervention sociale, 2003. Disponível em: $<\mathrm{http} / / /$ www.sepsac.org/uploads/media/Empowerment_et_intervention_sociale_-_ninacs.pdf $>$. Acesso em: 21 jun. 2005.

PATRICK M. Identity, diversity and politics of recognition. In: NEIL, O'Sullivan (Ed.). Political theory in transition. London: Routledge, 2000. p. 33-46. [2000 cit. in Canteli, 2006, p. 5.]

PAUGAM, Serge (Org.). Repenser la solidarité: 1'apport des sciences sociales. Paris: PUF, 2007.

ROSANVALLON, Pierre. La nouvelle question sociale: repenser l'État-providence. Paris: Éditions du Seuil, 1995. La crise de l'État-providence. Paris: Éditions du Seuil, 1984.

SOULET, Marc-Henry. Une solidarité de responsabilisation. In: ION, J. (Ed.). Le travail social en débat[s]. Paris: La Découvert, 2005. p. 86-103.

. Le travail social paliatif: entre réduction des risques et intégration relative. Cidades - Comunidades e Territórios, n. 15, p. 11-27, 2007.

SOYDAN, Haluk. La historia de las ideas en el trabajo social. Valência: Tirant lo Blanch, 2003.

WEBB, Stephan. Social work in a risk society: social and political perspectives. Nova York: Palgrave Macmillan, 2006.

WHULL, Simon. L'insertion, les politiques en crise. Paris: PUF, 1996. 